\title{
AS CONTRIBUIÇÕES DA EDUCAÇAO FÍSICA NA FORMAÇÃO INTERCULTURAL DE PROFESSORES INDÍGENAS NA UFG
}

\author{
THE CONTRIBUTIONS OF PHYSICAL EDUCATION IN THE INTERCULTURAL \\ TRAINING OF INDIGENOUS TEACHERS IN UFG
}

\author{
LAS CONTRIBUCIONES DE LA EDUCACIÓN FÍSICA EN LA FORMACIÓN \\ INTERCULTURAL DE PROFESORES INDÍGENAS EN LA UFG
}

Tiago Onofre da Silva

E-mail: tiagoonofre007@gmail.com

Universidade de Brasília - UnB

Francisco Luiz de Marchi

E-mail: demarchiufg@gmail.com

Wilson Luiz Lino de Sousa

E-mail: wilson.lino.sousa@gmail.com

Universidade Federal de Goiás - UFG

\begin{abstract}
RESUMO
No presente artigo pretende-se relatar uma experiência com o processo de formação de professores indígenas, no âmbito da educação física, realizado na Faculdade de Educação Física em janeiro de 2009. A formação de professores indígenas - Licenciatura Intercultural - é organizada pela Faculdade de Letras da UFG, tendo por objetivo a formação de professores para atuarem no ensino fundamental e médio das escolas indígenas. Dentre os conteúdos tratados no currículo do referido curso se encontra o tema contextual esporte e lazer, parte integrante da matriz de formação básica do professor. O texto ora apresentado se refere aos processos formativos do professor indígena, no que tange às trocas interculturais de conhecimentos acerca das manifestações da cultura corporal, em especial no esporte e lazer, tendo como metodologia norteadora do processo a pedagogia histórico-crítica. Concluise que o processo de formação se deu de forma proveitosa resultando numa rica troca de conhecimentos e experiências acerca do Esporte e do Lazer.
\end{abstract}

PALAVRAS-CHAVE: Licenciatura Intercultural. Educação Física. Pedagogia Histórico-Crítica

\section{ABSTRACT}

In this paper we intend to report an experience with the process of training indigenous teachers in the field of physical education, held at the Faculty of Physical Education in January 2009. The training of indigenous teachers - Intercultural Licenciatura - is organized by the Faculty of Letters of the UFG, aiming the training of teachers to work in elementary and secondary education of indigenous schools. Among the contents covered in the curriculum of the referred course is the contextual theme of sport and leisure, an integral part of the teacher's basic training matrix. The present text refers to the formative processes of the indigenous teacher, regarding the intercultural exchanges of knowledge about the manifestations of the corporal culture, especially in the sport and leisure, having as a guiding methodology of the process the historical-critical pedagogy. It is concluded that the training process was fruitful, resulting in a rich exchange of knowledge and experiences about Sport and Leisure.

KEYWORDS: Intercultural Degree. Physical Education. Historical-Critical Pedagogy

\section{RESUMEN}

En el presente articulo se pretende relatar una experiencia con el proceso de formación de profesores indígenas, en el ámbito de la educación fisica, realizado en la Facultad de Educación Física en enero de 2009. La formación de profesores indigenas - Licenciatura Intercultural - es organizada por la Facultad de Letras de la UFG, teniendo

V.11

n.3 p. $198-211$

Set./Dez. 
como objetivo la formación de profesores para actuar en la enseñanza fundamental y media de las escuelas indigenas. Entre los contenidos tratados en el currículo de dicho curso se encuentra el tema contextual deporte y ocio, parte integrante de la matriz de formación básica del profesor. El texto ora presentado se refiere a los procesos formativos del profesor indígena, en lo que se refiere a los intercambios interculturales de conocimientos acerca de las manifestaciones de la cultura corporal, en especial en el deporte y el ocio, teniendo como metodología orientadora del proceso la pedagogía histórico-crítica. Se concluye que el proceso de formación se dio de forma provechosa resultando en un rico intercambio de conocimientos y experiencias acerca del Deporte $y$ del Ocio..

PALABRAS-CLAVE: Licenciatura Intercultural. Educación Física. Pedagogía Histórico-Crítica

\section{INTRODUÇÃO}

Este trabalho originou-se da elaboração e desenvolvimento de uma experiência de formação com o Tema Contextual Esporte e Lazer como conteúdo obrigatório na matriz de formação básica do professor indígena pela Licenciatura Intercultural.

Apresentaremos, inicialmente, e de forma sucinta, o processo de construção do curso de Licenciatura Intercultural. Em seguida o Tema Contextual Esporte e Lazer, no âmbito curricular do curso e, na sequência, a fundamentação teórica, bem como, as estratégias de ensino desenvolvidas.

De acordo com o Projeto Político Pedagógico do Curso (UFG, 2006), a elaboração da Licenciatura Intercultural se deu com a participação de professores e lideranças indígenas dos Estados de Goiás, Tocantins, Maranhão, Roraima e Rondônia que estiveram presentes em seminários realizados na UFG. Realizou-se também reuniões nas aldeias com o propósito de discutir o projeto. Contou ainda com a participação de especialistas representantes do Ministério da Educação, Fundação Nacional do Índio e Centro de Trabalhos Indigenistas que apresentaram suas sugestões sobre políticas educacionais e a atual situação escolar indígena do país durante seminário que se realizou em Goiânia, no período de 18/04/05 a 20/04/05.

A proposta inspirou-se em experiências com cursos de formação de professores indígenas a nível de magistério, o caso do curso "30 Grau Indígena", da Universidade do Mato Grosso - UNEMAT e o curso "Licenciatura Intercultural" da Universidade Federal de Roraima - UFRR. Destina-se aos povos indígenas que se situam na região dos rios Araguaia-Tocantins atendendo aos seguintes povos: Karajá (GO-TO-MT), Tapuio (GO), Avá-Canoeiro (GO-TO), Krahô (TO), Tapirapé, Xerente (TO), Apinajé (TO), Krikati(MA), Timbira e Guajajara. A inclusão destes num único projeto se justifica por possuírem uma semelhante relação com a sociedade não indígena e enfrentarem, cotidianamente, os mesmos problemas. 
O projeto tem como eixos de sustentação os temas "Diversidade" e "Sustentabilidade". Se justificam por se basear na realidade das sociedades indígenas, no reconhecimento da diferença étnica, na situação em que cada comunidade vive e no seu relacionamento com os outros povos.

O objetivo do curso foi formar e habilitar professores indígenas em Licenciatura Intercultural, para lecionar nas escolas de níveis Fundamental e Médio, com vistas a atender a demanda da comunidade local indígena por professores com formação superior.

\section{O CURRÍCULO}

De acordo com o projeto, o currículo constitui-se da matriz de Formação Básica, com duração de dois anos e três matrizes de Formação Específica, com duração de três anos. Estas últimas serão destinadas à especialização dos Professores indígenas. As matrizes de Formação Básica do Professor e as de Formação Específica são compostas de temas referenciais, áreas de conhecimento e temas contextuais.

Os temas referenciais - interculturalidade, diversidade e diferença, identidade/etnicidade, autonomia e alteridade - são indicadores de que perspectiva os temas contextuais deverão ser trabalhados.

Encontramos assim, no Quadro 1, com base nos eixos referenciais, a matriz Curricular básica do curso:

QUADRO 1 - MATRIZ CURRICULAR BÁSICA DO CURSO INTERCULTURAL INDÍGENA UFG

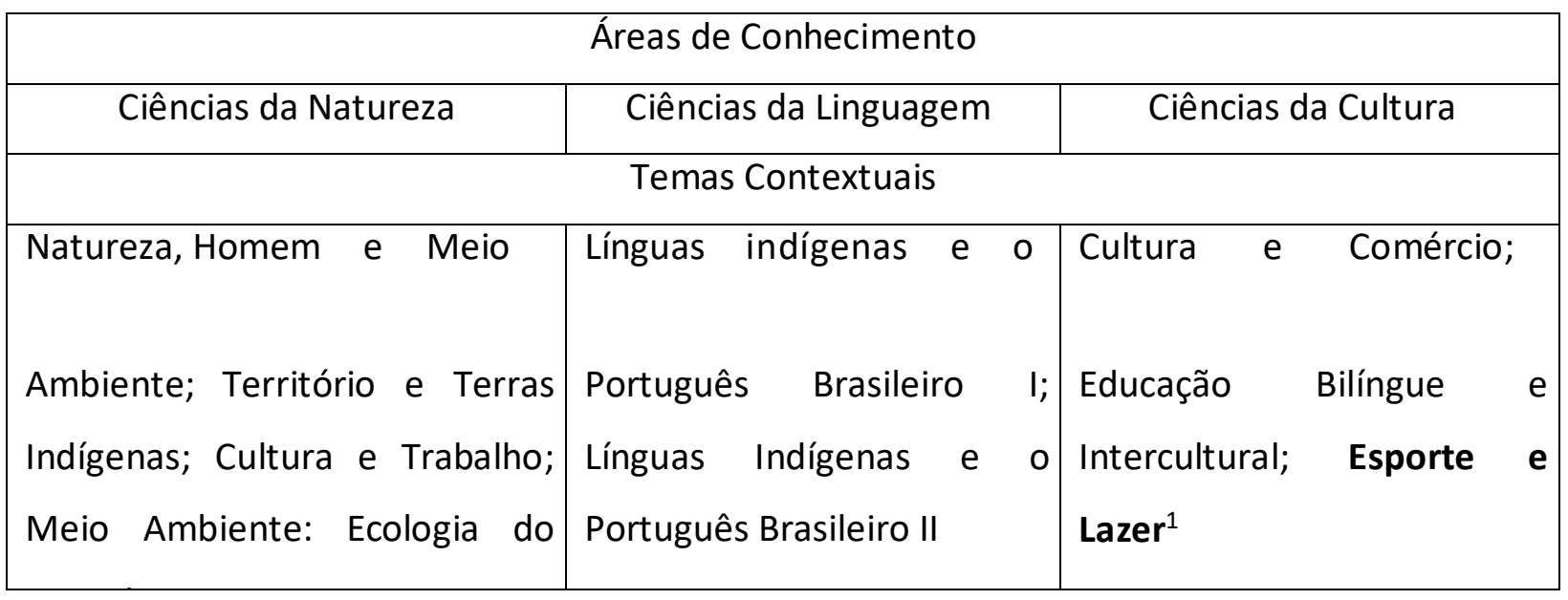

\footnotetext{
${ }^{1}$ Grifo nosso.
} 


\section{CONSTRUINDO O TEMA CONTEXTUAL - ESPORTE E LAZER}

A ementa do tema contextual - Esporte e Lazer trata "o esporte no campo da arte, cultura e cidadania, como um meio para promover a autoestima e estimular o intercâmbio cultural, fortalecendo, de modo positivo, as relações intraculturais e interculturais". (Cf. UNIVERSIDADE FEDERAL DE GOIAS/FACULDADE DE LETRAS, 2006). Seguindo a proposição ementária, elaboramos os seguintes objetivos para tema contextual Esporte e Lazer:

$\checkmark$ Identificar procedimentos que viabilizem uma intervenção pedagógica condizente com princípios educativos, éticos e políticos a partir da experimentação/vivência de manifestações esportivas e de lazer, da reflexão sobre as experiências concretas dos alunos envolvidos;

$\checkmark$ Capacitar o desenvolvimento de um programa que valorize o Esporte e o Lazer e suas importantes relações com a cultura indígena;

$\checkmark$ Valorizar a avaliação crítica como recurso necessário à qualificação da prática pedagógica do esporte e do lazer.

Visando atingir os objetivos propostos elaboramos as seguintes temáticas:

$\checkmark$ Esporte, Lazer e Jogos;

$\checkmark$ Esporte Lazer e Jogos: Oficina de Peteca;

$\checkmark$ Futebol e Inclusão;

$\checkmark$ Práticas Corporais e Saúde;

$\checkmark$ Painel de Avaliação.

Tendo em vista tratar-se de uma experiência intercultural o que se buscou foi a interação entre as culturas, valorizando-as, favorecendo o convívio e a integração assente numa relação não hierarquizada, mas baseada no respeito pela diversidade e no enriquecimento mútuo. Foi nossa intenção apreender e compreender quais as práticas que os alunos-professores identificavam como esportivas e/ou de lazer, tendo em vista a dinâmica cotidiana em suas aldeias e apresentar-lhes as nossas. 


\section{METODOLOGIA DE ENSINO}

A partir da experimentação/vivência de manifestações esportivas e de lazer e da reflexão sobre as experiências cotidianas dos alunos envolvidos, foram desenvolvidos os tópicos relacionados no programa, buscando aprofundá-los por meio de aulas expositivasdialogadas e do desenvolvimento de atividades lúdicas e ludo-esportivas.

A proposta metodológica teve por referência a Pedagogia Histórico-Critica, em especial, os procedimentos didáticos apontados por Gasparini (2002). Conforme este autor, o procedimento é constituído por cinco etapas: Pratica Social Inicial, Problematização, Instrumentalização, Catarse e Prática Social Final.

A primeira, denominada Prática Social Inicial, constitui o ponto de partida, a realidade social mais ampla dos alunos em relação ao conteúdo, ou seja, o que trazem de conhecimento a partir das suas vidas cotidianas.

Neste sentido, o autor afirma que

O interesse do professor por aquilo que os alunos já conhecem é uma ocupação prévia sobre o tema que será desenvolvido. É um cuidado preliminar que visa saber quais as "pré-ocupações" que estão nas mentes e nos sentimentos dos escolares. Isso possibilita ao professor fazer um trabalho pedagógico mais adequado, a fim de que os educandos, nas fases posteriores do processo, apropriem-se de um conhecimento significativo para suas vidas. (GASPARIN, 2002, p. 16).

Com o objetivo de conhecermos o que os alunos sabiam acerca dos temas, propusemos as seguintes estratégias sintetizadas no Quadro 2 a seguir:

QUADRO 2 - ESTRATÉGIAS DE APREENSÃO DA PRÁTICA SOCIAL INICIAL DOS ALUNOS SOBRE OS TEMAS DO CURSO

\begin{tabular}{|c|c|c|}
\hline Esporte, Lazer e Jogos & $\begin{array}{c}\text { Práticas Corporais e } \\
\text { Saúde }\end{array}$ & Futebol e Inclusão \\
\hline
\end{tabular}




\begin{tabular}{|c|c|c|}
\hline Organização por grupos Etnicos; & $\begin{array}{l}\text { Organização em pequenos } \\
\text { grupos }\end{array}$ & Trabalho Individual: \\
\hline $\begin{array}{l}\text { 1. Divisão em subgrupos com no } \\
\text { máximo } 5 \text { alunos-professores; } \\
\text { 2. Apresentação dos membros: } \\
\text { breve comentário sobre cada um } \\
\text { (o que identifica / habilidades } \\
\text { /qualidades). } \\
\text { 3. Elaboração e apresentação de } \\
\text { uma síntese sobre os } \\
\text { conhecimentos do grupo sobre: } \\
\text { Esporte, Lazer e Jogo. }\end{array}$ & $\begin{array}{l}\text { 1. Registrar (na folha) os } \\
\text { conhecimentos que cada } \\
\text { um tem, ou pensa sobre a } \\
\text { saúde e as suas relações } \\
\text { na vida. } \\
\text { 2. Discussão no Grupo; } \\
\text { 3. Apresentação de Síntese } \\
\text { para a Turma. }\end{array}$ & $\begin{array}{l}\text { 1. Redação: O Futebol } \\
\text { em minha vida } \\
\text { Trabalho em Grupo: }\end{array}$ \\
\hline
\end{tabular}

A partir desta metodologia, apreendemos que os temas expressam as maneiras particulares de compreensão de cada um dos povos diversificando os sentidos e significados. Em linhas gerais, no caso do tema "Esporte, Lazer e Jogos", não houve uma distinção clara entre Esporte e Jogo, tratados inclusive como sinônimos e, quando diferenciados, os únicos aspectos identificados foram a presença ou não de regras (Se há regras é Esporte, se não há é Jogo) e a presença ou não de premiação. No caso do conceito de Lazer, o mesmo foi compreendido enquanto momento de divertimento, de prazer em que se dedicavam, conforme algumas manifestações, ao banho de rio, ao namoro e aos jogos.

A partir das respostas iniciais, demos início ao segundo passo, de Problematização, de questionamentos acerca das concepções identificadas. Por exemplo: O jogo não possui regras? O que diferencia as regras do Jogo e do Esporte? É possível atribuir premiação dentro do jogo? Esporte é Lazer? Esporte é Saúde? Este foi um momento importante e serviu de norteador para todo o processo didático pedagógico. Foi o elo de ligação da prática com a teoria, do conhecimento cotidiano com o elaborado. Foi o momento em que a prática inicial, posta em questão, foi analisada, interrogada coletivamente. Nesse momento foram apresentadas e discutidas as razões pelas quais os alunos deveriam aprender o conteúdo proposto, não por si mesmo, mas em função de necessidades sociais. (GASPARIN, 2002).

Abaixo, no Quadro 3, temos a síntese das principais questões-problemas:

QUADRO 3 - QUESTÕES-PROBLEMAS SOBRE AS TEMÁTICAS TRABALHADAS Esporte, Lazer e Jogos 


\begin{tabular}{|c|c|c|}
\hline Por que as pessoas jogam? & Qual o conceito de saúde? & $\begin{array}{l}\text { Há diferença entre o futebo } \\
\text { jo go e o futebol esporte? }\end{array}$ \\
\hline Para vencer? & & \\
\hline $\begin{array}{l}\text { Para sobrepujar? } \\
\text { Para se divertir? }\end{array}$ & $\begin{array}{l}\text { Qual diferença entre } \\
\text { exercício físico e atividade } \\
\text { física? }\end{array}$ & E o futebol lazer? \\
\hline Para inventar? & O que são: hábitos saudáveis? & $\begin{array}{l}\text { Quais os tipos de futebol } \\
\text { que conhecemos? }\end{array}$ \\
\hline
\end{tabular}

Visando qualificar as discussões levantadas, caminhamos, então, para a etapa seguinte, a Instrumentalização. Segundo Gasparini (2002), este é o momento no qual o conhecimento sistematizado é posto à disposição dos alunos, estabelecendo uma comparação intelectual entre os conhecimentos cotidianos e os sistematizados. Essa comparação não deve ocorrer como negação dos primeiros, uma vez que o 'novo conhecimento' é sempre elaborado sobre o que já se conhece de antemão.

Este é o momento crucial e que ocupa a maior parte do processo de formação. É neste momento que se justifica a necessidade de uma formação teórico-metodológica dos alunosprofessores indígenas, a apropriação de conhecimentos, técnicas e procedimentos. Este processo lhes permite compreender melhor a relação/diferenciação entre as expressões trabalhadas e qualificam, pela escolarização, as próprias leituras e expressões destes fenômenos, tornando-os cada vez mais desenvolvidos. Para dialogarmos sobre nossas práticas apresentamos e discutimos, por exemplo, os conceitos Esporte e de Lazer.

Para o primeiro recorremos às elaborações de Bracht (2005 págs. 9-10), para quem o esporte é uma prática social situada no quadro da cultura corporal, "surgida no âmbito da cultura europeia do século XVIII, com caráter competitivo, cuja execução repousa essencialmente sobre uma ideia de luta contra um elemento definido: uma distância, uma duração, um obstáculo, uma dificuldade material, um perigo, um adversário".

O lazer foi tratado a partir das contribuições de Fernando Mascarenhas (2003 pág.97), que o concebe como um "fenômeno tipicamente moderno, resultante das tensões entre capital e trabalho, que se materializa como um tempo e espaço de vivências lúdicas, lugar de organização da cultura, perpassado por relações de hegemonia".

Esse procedimento não visou, apenas, que o aluno-professor indígena viesse a se apropriar dos conceitos, mas, sobretudo, estabelecer um diálogo com os mesmos. Que se 
tornasse possível a comunicação entre nós, de modo que quando propuséssemos as atividades e a elas nos referíssemos como pratica esportiva, que nossos interlocutores, os alunosprofessores, compreendesse-nos. Não buscamos, deste modo, uma apropriação mecânica dos conceitos trabalhados, mas adequando-os e relacionando-os justamente com as práticas e as vivências cotidianas levantadas anteriormente.

Esperávamos, também, que os mesmos, doravante, fizessem uso do conhecimento que estavam se apropriando. Segundo Gasparini (2002) a apropriação acontece, inicialmente, a partir da análise do conhecimento sistematizado, para, posteriormente, ocorrer a síntese do novo conhecimento adquirido. A síntese, então, se constitui na etapa seguinte do processo, qual seja, a Catarse. Esta seria, segundo o autor de referência, a síntese do cotidiano e do científico, do teórico e do prático, é a manifestação do novo conceito adquirido. Tratase da manifestação teórica do nível de conhecimento alcançado pelo aluno, por meio da elaboração teórica e expressão prática da nova síntese.

Dando continuidade ao desenvolvimento do processo de ensino-aprendizagem, norteados pela proposta teórico-metodológica assumida, propusemos, um conjunto de atividades, que serão apresentadas na sequência, e que visavam evidenciar a "expressão prática da nova síntese" dos professores indígenas. Buscamos também dar início ao que seria a "elaboração teórica da nova síntese", tanto pela experimentação das atividades propostas, quanto pela realização de um processo avaliativo que possibilitou a elaboração de painéis expositivos dos novos conhecimentos adquiridos e reconstruídos. Quando do momento de exposição foi solicitado pelos alunos-professores que a apresentação fosse bilíngue, primeiro em português, cumprindo a etapa avaliativa e as formalidades da Universidade, e a segunda na língua de cada etnia, uma vez que as apresentações foram gravadas e seriam apresentadas, na aldeia, para os seus alunos, parentes e demais integrantes daquela comunidade.

Por fim o caminho metodológico segue o seguinte percurso espiralado:
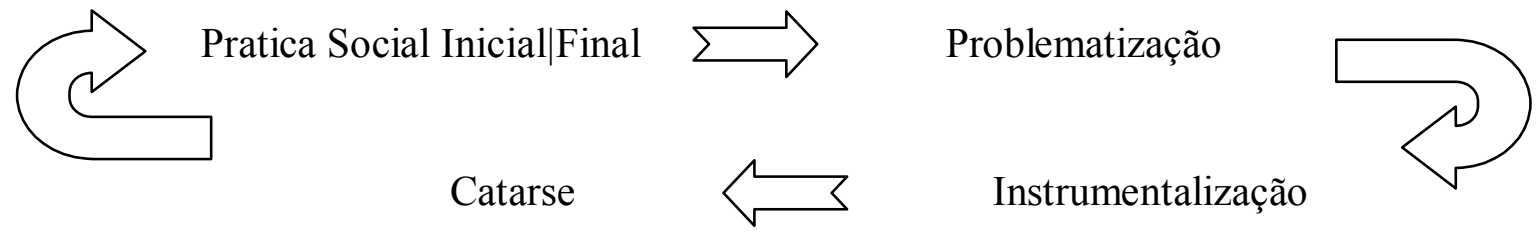

\subsection{OFICINA DE PETECA}

Esta atividade, planejada para ser desenvolvida em $8 \mathrm{~h} / \mathrm{a}$, teve por objetivos: 

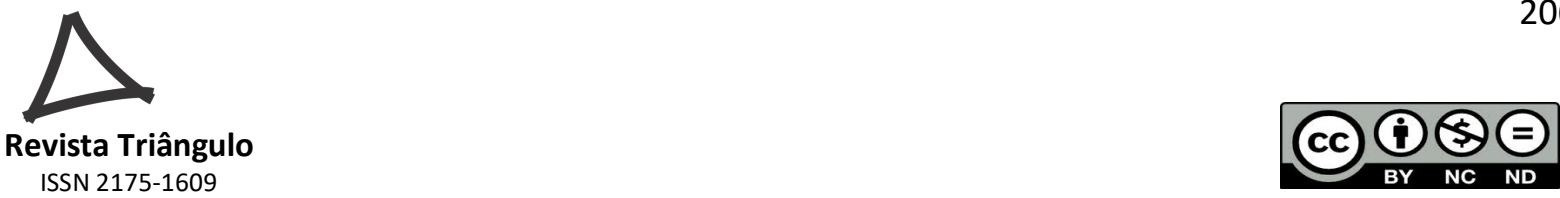

$\checkmark$ Experimentar o jogo de peteca e identificar sua presença no cotidiano urbano e nas aldeias;

$\checkmark$ Produzir petecas com material reciclado;

$\checkmark$ Adequar as instalações da quadra às diversas formas de se jogar peteca;

$\checkmark$ Identificar, e discutir, o processo de esportivização do jogo de peteca, no Brasil

Inicialmente foi solicitação aos alunos-professores um levantamento, via internet, sobre as possibilidades de construção da peteca com materiais reciclados e o levantamento de artigos acadêmico-científico que tematizasse o jogo/prática da peteca. Para tanto, utilizou-se o Laboratório de Informática da OfivcimBiblioteca Central da UFG (Figura 1), de modo a possibilitar a cada aluno-professor ou aluna-professora participante a experiência na utilização dos equipamentos, bem como, realização da referida busca. As diretrizes encontradas foram utilizadas para orientar o planejamento coletivo da atividade. $\mathrm{O}(\mathrm{s})$ artigo(s) levantados deveriam ser lidos e o seu conteúdo utilizado para fundamentar a discussão sobre a diferença entre jogo e esporte. Por outro lado, o conjunto da experiência deveria nortear as reflexões sobre as práticas da cultura corporal em nossos dias, nos contextos urbanos e das aldeias.

\section{FIGURA 1- LABORATÓRIO DE INFORMÁTICA DA BIBLIOTECA CENTRAL UFG}

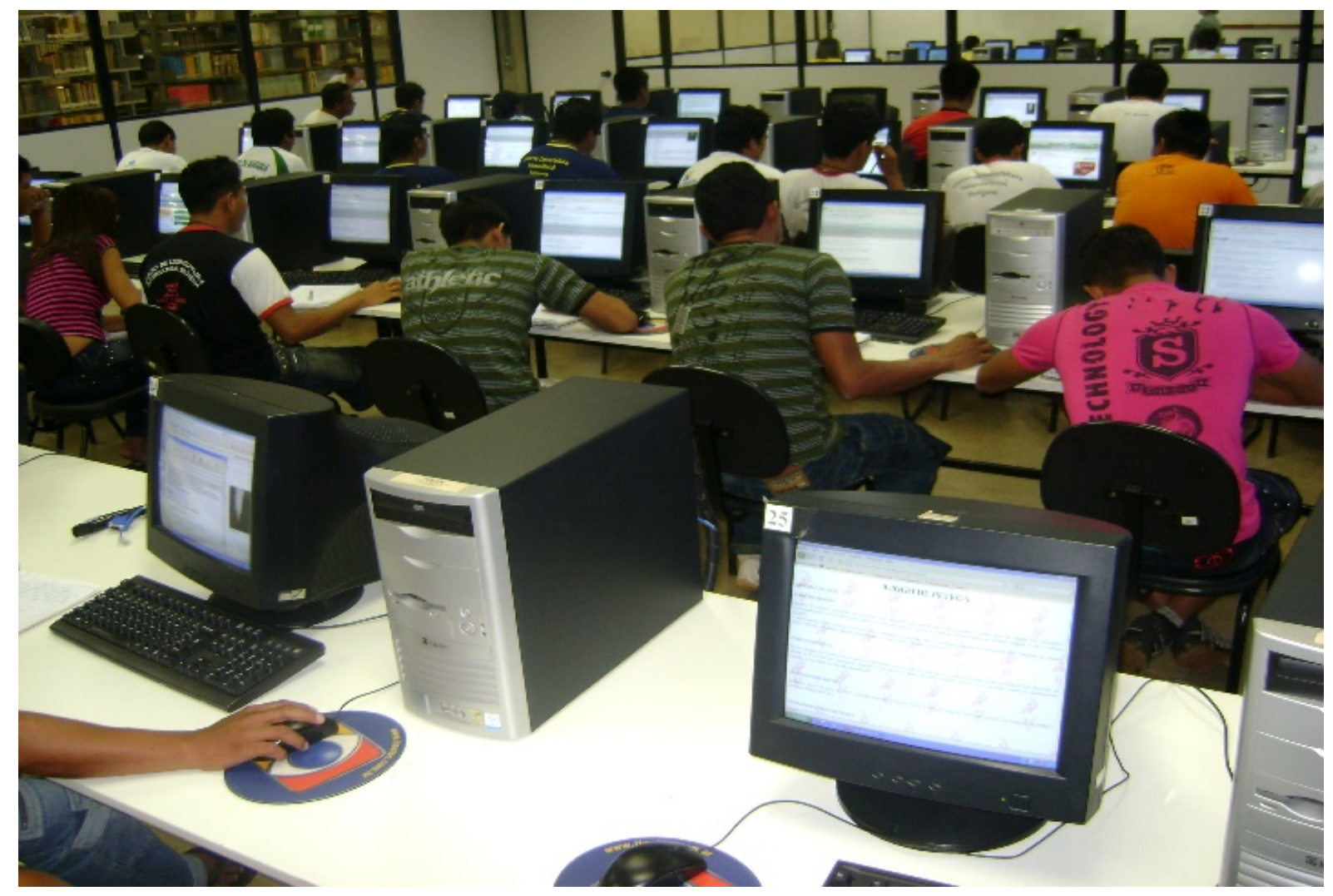

Fonte: Registro Próprio 
Num segundo momento nos reunimos no Ginásio de Esporte da FEFD/UFG, para produzirmos as petecas, organizarmos os jogos e ao final nos reunirmos, em roda de conversa, para dialogarmos sobre a experiência (Figura 2).

FIGURA 2 - OFICINA DE PETECA

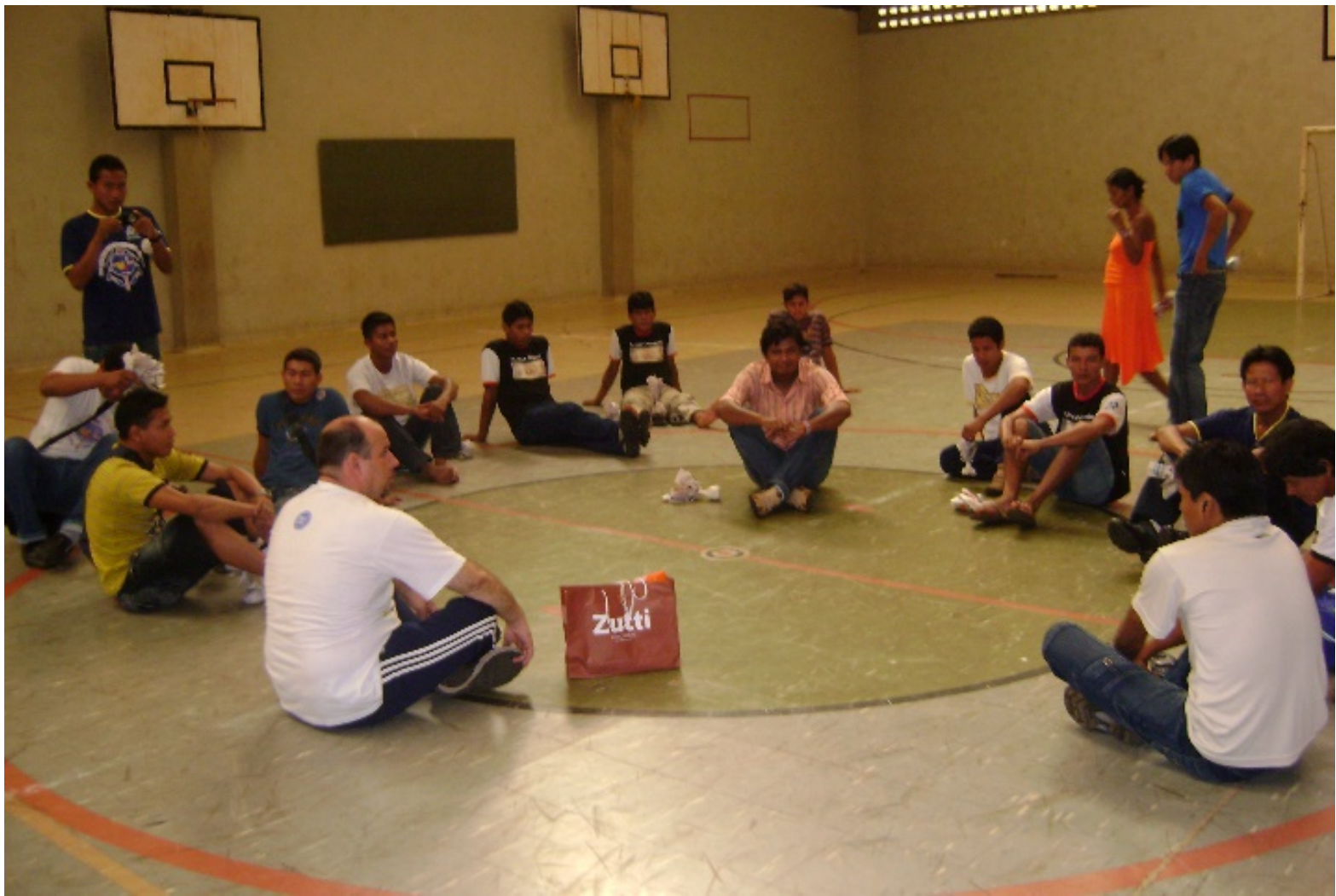

Fonte: Registro Próprio

Evidenciou-se que os alunos-professores e alunas-professoras reconhecem a prática, conhecem o jogo, e sua presença no cotidiano das aldeias, apenas entre as crianças e de forma desvalorizada. Ao compreender como a peteca, por meio do jogo e da prática esportiva, se faz presente no contexto urbano, vários participantes da oficina afirmaram reconhecer a necessidade da problematização destas práticas nas escolas e na comunidade, no sentido de valorizar suas práticas e sua cultura. 

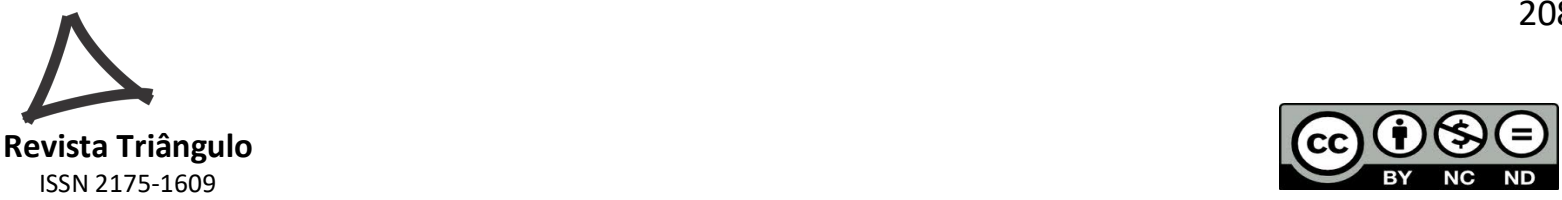

\section{FIGURA 3 - VIVÊNCIA DA OFICINA DE PETECA}

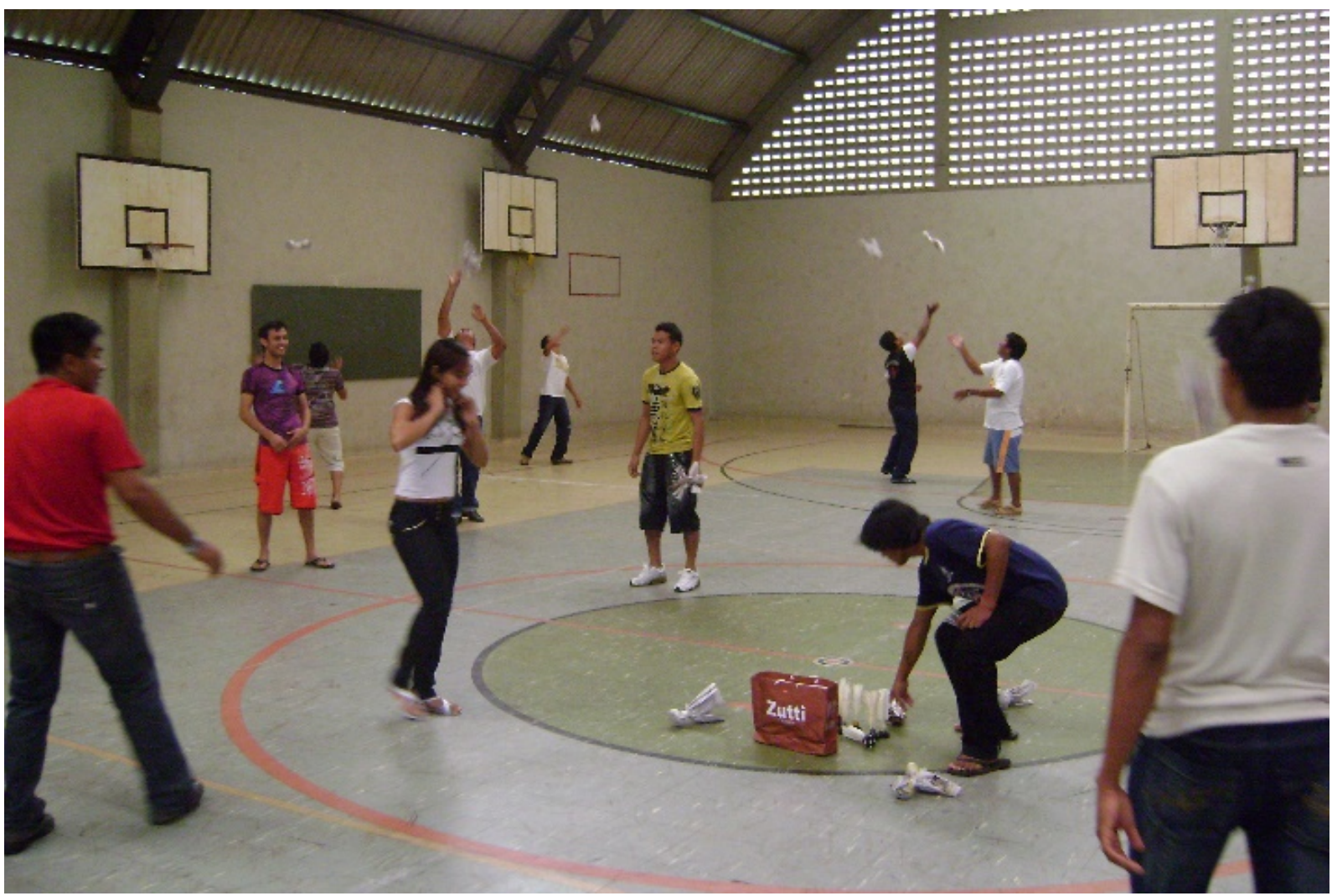

Fonte: Registro Próprio

O espaço dialógico para a comunicação possibilitou, ainda, identificar valorização da ludicidade da experiência. O jogo e o esporte foram analisados a partir desse conceito e as implicações para a sua utilização no contexto escolar, bem como, para a sua introdução no cotidiano das aldeias também foi discutido. Identificou-se a necessidade do planejamento e, neste, da adequada elaboração de um Plano de Ensino, no qual se registre, de modo claro, os objetivos, os métodos/estratégias, os conteúdos e os processos de avaliação.

A atividade foi oportuna, por valorizar aspectos da cultura dos participantes, evidenciar a presença da peteca tanto nas aldeias como no contexto urbano, permitir o diálogo sobre a diferente valorização da prática entre as culturas. A valorização do aspecto lúdico foi identificada, também, como facilitadora do diálogo e da relação entre professores e alunosprofessores e alunas-professoras.

\subsection{FUTEBOL DE SEIS QUADRADOS}

Primeiramente justificamos a escolha do conteúdo Futebol por ter se apresentado, nas discussões levantadas durante a "Prática Social Inicial", a manifestação da Cultura Corporal de 
maior presença e conhecimento entre os alunos-professores. Além de ser um conteúdo de maior abrangência, este carregava em si, pelos conhecimentos manifestados, enquanto Esporte, sobretudo masculino e essencialmente brasileiro.

Propusemos, de início, demonstrar que o Futebol, a partir dos conceitos expostos, pode manifestar-se como Jogo e também como Esporte, sendo, portanto, produto de criação humana dentro de um determinando contexto histórico-social. Desta forma, identificou-se jogos indígenas que se assemelhassem com o futebol tendo como característica principal o fato de ser jogado com os pés e mediado pela presença de uma bola. Além da contextualização, buscou-se identificar as diferentes manifestações do Futebol, tais como: Futebol de Areia; de Salão, de Sabão, Virtual, de Botão, de Rua, entre outros.

O segundo momento foi demonstrar que, fruto das determinações histórico-sociais, portanto, culturais, o futebol, manifestado enquanto Jogo e Esporte, foi apropriado e relacionado ao gênero masculino e, mais recentemente, ao gênero feminino. Por ser fruto de uma criação humana, trata-se de uma prática corporal do Gênero Humano e não restrito aos gêneros masculino ou feminino. Interessante relatar que, durante o processo de problematização do tema, um dos povos relatou que o jogo do futebol era praticado no seu contexto pelas mulheres e os homens só participavam mediante autorização das mesmas.

O terceiro e principal momento foi a sugestão/vivência teórico-metodológica de ensino, enquanto jogo e esporte, do chamado "Futebol de seis quadrados" (Figuras 4 e 5). O objetivo era construir um espaço de jogo alternativo que se dividisse em seis espaços ou quadrados. Cada espaço seria ocupado por um jogador de cada equipe, compondo seis jogadores, sendo cada um responsável apenas pelo seu “quadrado". A ideia geral era permitir, num espaço maior de jogo, seja quadra, ou campo, seis pequenos espaços de jogo, aos quais seria possível, em cada um, inserir mulheres, crianças, idosos, cadeirantes, entre outros que compusessem coletivamente o time de seis jogadores. 


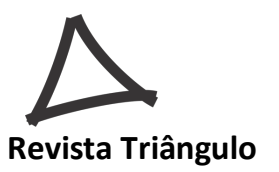

ISSN 2175-1609

FIGURA 4 - OS SEIS QUADRADOS DO FUTEBOL

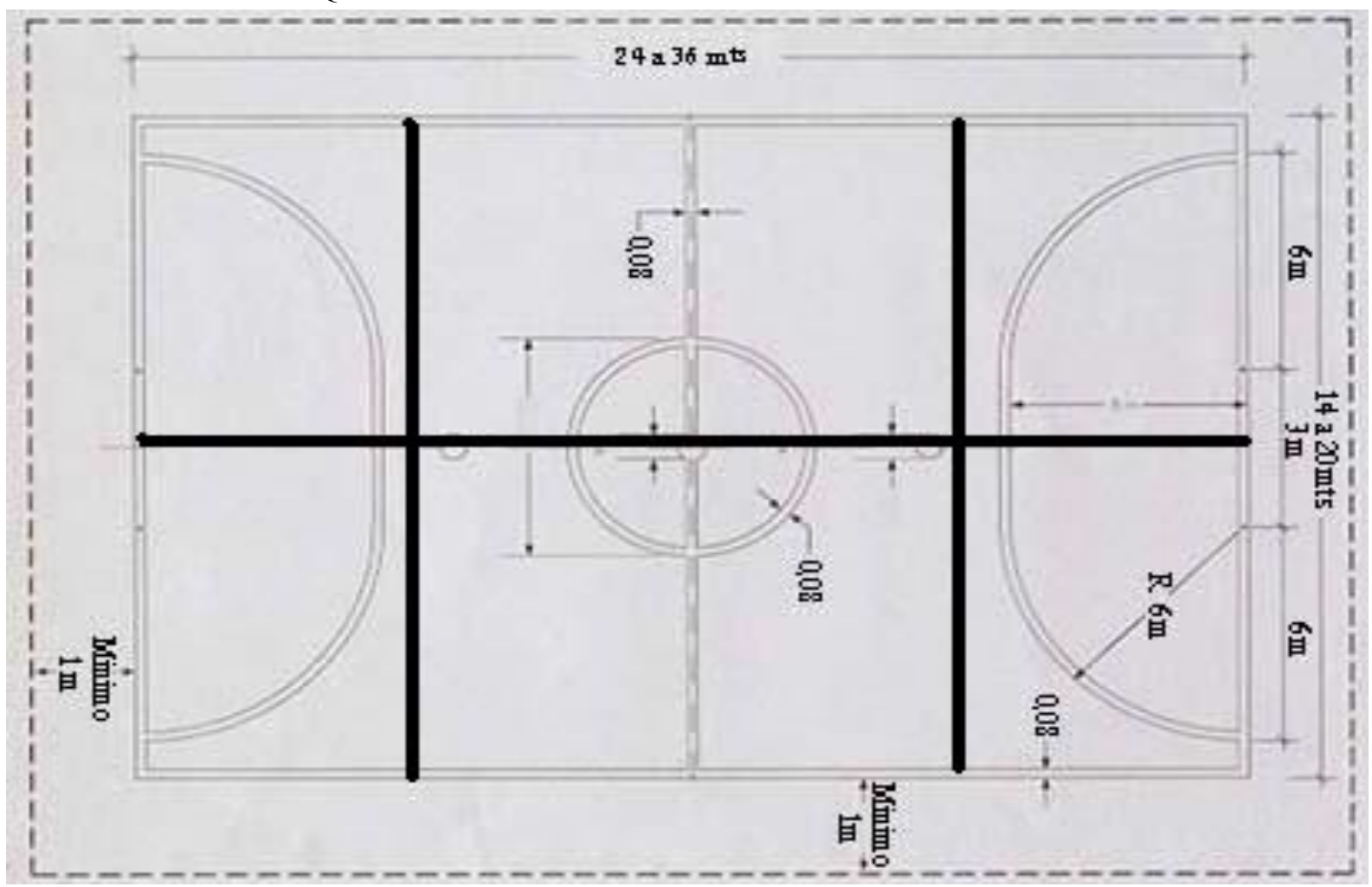

Fonte: Registro Próprio

FIGURA 5 - VIVÊNCIA DO FUTEBOL DE SEIS QUADRADOS

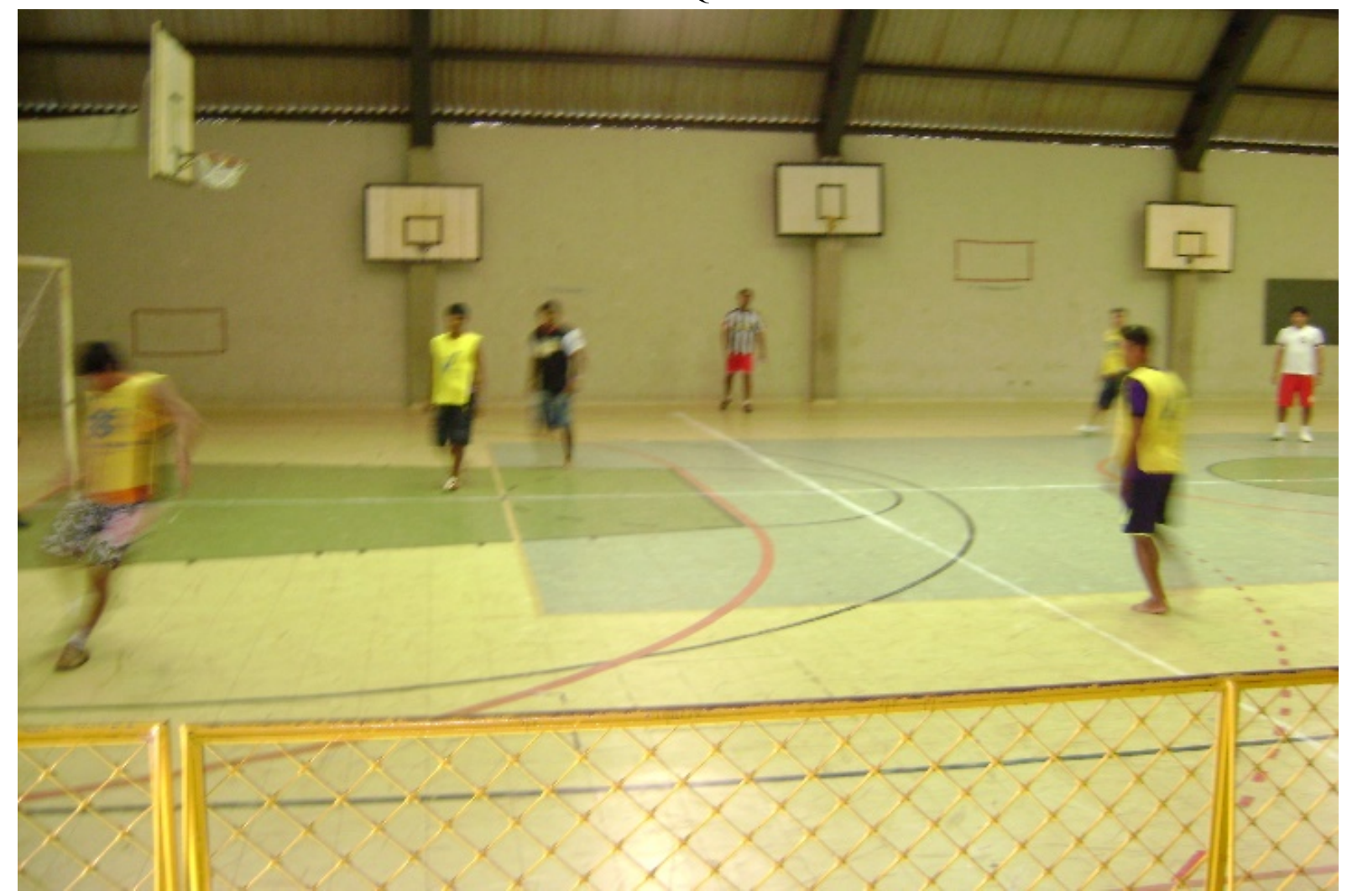

Fonte: Registro Próprio 
O propósito foi demonstrar que o Futebol, apesar de já possuir características consolidadas por meio do Jogo ou do Esporte, num contexto escolar, pode (e deve) ser modificado e recriado, possibilitando múltiplas variações atendendo a diversas necessidade. $\mathrm{O}$ Futebol de seis quadrados na escola seguiria regras, contextos, objetivos e finalidades a partir dos sujeitos, numa relação de ensino aprendizagem, que conferiam novos sentidos e significados.

\section{CONSIDERAÇÕES FINAIS}

O processo de formação de professores indígenas se deu de forma muito proveitosa, tanto para o corpo docente, quanto para os professores indígenas participantes. Resultou em uma rica troca de conhecimentos e experiências acerca do Esporte e do Lazer.

Ainda que a última etapa do procedimento didático da pedagogia histórico-crítica, a Pratica Social Final, não tenha sido trabalhada plenamente no curso, apenas uma aproximação rápida da mesma, só passa a ganhar força na prática cotidiana dos professores, prática essa repensada através da metodologia utilizada no tema contextual Esporte e Lazer.

A Pedagogia Histórico-Crítica se apresentou como ferramenta metodológica importante para o trato do conhecimento, em específico, na licenciatura intercultural. A participação da Faculdade de Educação Física na Licenciatura Intercultural veio a reforçar o lugar da instituição dentro do curso, fortalecendo assim, a instituição e a Licenciatura oferecida.

\section{REFERÊNCIAS}

BRACHT, V. Sociologia crítica do esporte: uma introdução. 3. ed. Ijuí: Unijuí, 2005.

GASPARIN, João Luiz. Uma didática para a pedagogia histórico-crítica. 2002.

KUNZ, Elenor. Transformação Didático-Pedagógica do Esporte. Ijuí: Uniu, 1994.

MASCARENHAS, Fernando. Lazer: como prática da liberdade, uma proposta educativa para a juventude. Goiânia: Ed. UFG, 2003.

SOARES, Carmen Lúcia, et al. Metodologia do ensino de educação física. Cortez Editora, 1992.

UFG. Núcleo Takinahaky de Formação Superior Indígena. Projeto Político Pedagógico

Educação Intercultural. Goiânia. 2006 